\title{
Alêushbra
}

IN' 2596-2671

Revista AlembrA - RA Confresa-MT

Volume 3. Número 6. Janeiro a junho 2021

\section{ARTHUR SCHOPENHAUER E A EXALTAÇÃO FILOSÓFICA DA MORAL CRIST T̃ EM PARA ALÉM DE BEM E MAL DE FRIEDRICH NIETZSCHE}

\author{
ARTHUR SCHOPENHAUER AND THE PHILOSOPHICAL EXALTATION OF CHRISTIAN \\ MORALS BEYOND GOOD AND EVIL OF FRIEDRICH NIETZSCHE
}

\author{
Josadaque Martins Silva ${ }^{1}$ \\ Cristiane da Silva Ferreira ${ }^{2}$ \\ Juliano Batista dos Santos $^{3}$
}

Recebido: 19/04/2021

Aceito: $14 / 06 / 2021$

Resumo: Este artigo tem por objetivo mostrar que no quinto capítulo, $\S 186$, de Para além de bem e mal, Nietzsche critica a pretensão clássica dos filósofos de fundamentar a moral e de formular uma ciência da moral, porém sem jamais indagar-se sobre o sentido da própria moral e sua problemática. E mais, expor que tal crítica nietzscheana atinge Arthur Schopenhauer, cuja fundamentação da moral estaria implícita na seguinte asseveração: "neminen laede, imo omines, quantum potes, iuva! - não faças mal a ninguém, mas antes ajuda a todos que puderes!". Portanto, a partir de uma leitura lógica e estrutural do Para além de bem e mal, § 186, investigaremos no que redundou esta tarefa schopenhaueriana de fundamentar a moral.

Palavras-chave: Moral Cristã; Tipologia; Schopenhauer; Fundamento da Moral.

Abstract: This article aims to show that in the fifth chapter, $\S 186$, Beyond Good and Evil, Nietzsche criticizes the classical pretension of philosophers to base morals and to formulate a science of morals, but without ever inking the meaning of one's own morals and its problematic. Moreover, to expose that such nietzschean criticism reaches Arthur Schopenhauer, whose foundation of morality would be implied in the following asseveration: "neminen laede, imo omines, quantum potes, iuva - Don't hurt anyone, but help everyone you can!". Therefore, from a logical and structural reading of Beyond Good and Evil, § 186, we will investigate in what resulted in this schopenhauerian task of basing morals.

Keywords: Christian Morality; Typology; Schopenhauer; Moral Foundation.

\section{Introdução}

\footnotetext{
${ }^{1}$ Mestre em Filosofia pela Universidade Federal de São Paulo (UNIFESP). Professor efetivo de Filosofia no Instituto Federal de Educação, Ciência e Tecnologia de Mato Grosso (IFMT), campus Cuiabá Cel. Octayde Jorge da Silva, Cuiabá, MT, Brasil. E-mail: josadaque.silva@cba.ifmt.edu.br

${ }^{2}$ Doutora em Língua Portuguesa pela Pontifícia Universidade Católica de São Paulo (PUC/SP). Professora efetiva de Língua Portuguesa e Literatura no Instituto Federal de Educação, Ciência e Tecnologia de Mato Grosso (IFMT), campus Cuiabá Cel. Octayde Jorge da Silva, Cuiabá, MT, Brasil. E-mail: cristiane.ferreira@cba.ifmt.edu.br

${ }^{3}$ Doutor em Estudos de Cultura Contemporânea pela Universidade Federal de Mato Grosso (UFMT). Professor efetivo de Filosofia no Instituto Federal de Educação, Ciência e Tecnologia de Mato Grosso (IFMT), campus Cuiabá Cel. Octayde Jorge da Silva, Cuiabá, MT, Brasil. E-mail: juliano.santos@cba.ifmt.edu.br
} 


\section{Alêsingbra'}

IS: 2596-2671

Revista AlembrA - RA Confresa-MT

Volume 3. Número 6. Janeiro a junho 2021

O pensamento de Friedrich Nietzsche evidencia suas inúmeras referências a Arthur Schopenhauer. Aliás, é a partir da leitura da obra $O$ mundo como vontade e representação, de Schopenhauer, que Nietzsche (1999) passa a se interessar pela filosofia. Porém, essa proximidade de Nietzsche com o corpus philosophicus schopenhaueriano não o impede de usar o seu martelo filosófico para criticar certas teses da filosofia de Schopenhauer, mormente, no que se refere à fundamentação da moral.

Em Para além de bem e mal, $\S 186^{4}$, Friedrich Nietzsche elabora a crítica à pretensão clássica dos filósofos de fundamentar a moral e de formular uma ciência da moral, sem, contudo, considerar detidamente o sentido da própria moral e sua problematização. Ao formular essa crítica, Nietzsche atinge Schopenhauer, cuja fundamentação da moral estaria implícita na sentença: "neminem laede, imo omines, quantum potes, iuva!"5 (SCHOPENHAUER, 1995, p. 44).

No presente estudo, objetivamos expor, em linhas gerais, no que redundou essa fundamentação da moral. Em outras palavras, qual a consequência dessa tarefa schopenhaueriana de fundamentar a moral, tal como Nietzsche a sugere em Para além de bem e mal, § 186 do capítulo Contribuição à história natural da moral. Para tanto, dividimos o artigo em quatro momentos. No primeiro, apresentamos o contraste que Nietzsche estabelece entre a sensibilidade moral e a ciência da moral, elucidando o porquê, segundo ele, a sensibilidade moral é refinada e, por outro lado, a ciência da moral é rudimentar. O segundo momento versa sobre a ciência da moral, a tipologia da moral e o problema da própria moral, uma vez que na perspectiva nietzscheana a ciência da moral é descrita como arrogante ao tentar fundamentar a moral. Não por acaso, ao contrário de fundamentar a moral, Nietzsche (2005) propõe uma tipologia que visa a descrever e a comparar as várias configurações de moral existentes culturalmente, donde a emergência dos verdadeiros problemas da moralidade. $\mathrm{O}$ terceiro momento descreve a fundamentação da moral perpetrada por Arthur Schopenhauer, cujo fundamento da moral é a compaixão. Por fim, no quarto momento, mostramos a crítica de Nietzsche à fundamentação da moral de Arthur Schopenhauer.

\footnotetext{
${ }^{4} \mathrm{O}$ texto de Para além de bem e mal ( $\left.\$ 186\right)$ utilizado nas citações pertence às seguintes traduções em língua portuguesa: NIETZSCHE, Friedrich Wilhelm. Obras incompletas. Seleções de textos de Gérard Lebrun; tradução e notas de Rubens Rodrigues Torres Filho; posfácio de Antônio Cândido. São Paulo: Nova Cultural, 1999. (Os Pensadores). / NIETZSCHE, Friedrich Wilhelm. Além do bem e do mal: prelúdio a uma filosofia do futuro. Tradução, notas e posfácio Paulo César de Souza. São Paulo: Companhia das Letras, 2005.

5 "Não faças mal a ninguém, mas antes ajuda a todos que puderes!". O texto de Sobre o fundamento da moral utilizado neste artigo pertence à seguinte tradução em língua portuguesa: SCHOPENHAUER, Arthur. Sobre o fundamento da moral. Tradução de Maria Lúcia Mello Oliveira Cacciola. São Paulo: Martins Fontes, 1995.
} 


\section{O contraste entre a sensibilidade moral e a ciência da moral}

O quinto capítulo de Para além de bem e mal trata da tentativa nietzscheana de constituir a história natural da moral, contrapondo as fundamentações morais engendradas pela tradição filosófica, especificamente, de Immanuel Kant e Arthur Schopenhauer. Decerto, na concepção de Nietzsche, tais fundamentações morais tendo como cerne a racionalidade ou a compaixão, de modo particular, controlam racionalmente as paixões, insistem na tarefa falaciosa de formular uma ciência da moral, corroboram a moralidade oriunda do pensamento socrático-platônico e da tradição judaico-cristã que tem o pretenso sentido compassivo, racional e universal e, por conseguinte, desnaturaliza a moral, enevoando a realidade histórica-natural de diversidades morais. Com isso, o capítulo supracitado "constitui uma espécie de pivô do livro" (GIACOIA JUNIOR, 2005, p. 43), tendo em vista que o aforismo 186, selecionado para análise neste artigo,

[...] contém o centro nevrálgico da genealogia nietzschiana da moral; dele se irradiam os mais importantes efeitos em termos de filosofia prática, que integrarão a si perspectivas diversas de análise do fenômeno moral, como as da psicologia, da história, da fisiologia, da semiologia (GIACOIA JUNIOR, 2005, p. 43).

Nietzsche principia o $§ 186$ de Para além de bem e mal ressaltando que,

na Europa de hoje [segunda metade do séc. XIX], a sensibilidade moral é tão sutil, tardia, múltipla, excitável, refinada, quanto a 'ciência da moral' que lhe corresponde é ainda jovem, incipiente, tosca e rudimentar - um atraente contraste, que às vezes se faz visível e toma corpo na pessoa mesma de um moralista (NIETZSCHE, 2005, p. 74, grifo do autor).

Nietzsche declara que na época dele havia um atraente contraste na Europa. Contraste denota a oposição entre coisas ou pessoas, quando comparadas, sendo que uma das quais faz sobressair a outra, por exemplo, o contraste entre a sombra e a luz. Desse modo, quando se alude ao contraste, apontam-se dois aspectos: um refinado e outro rudimentar. Se há um atraente contraste na Europa, então, algumas indagações podem ser suscitadas: "Entre o que ou quem se processa este contraste? Qual lado é refinado neste contraste, e qual lado é rudimentar?". Ora, conforme Nietzsche (2005), o contraste ocorre entre a sensibilidade moral e a ciência da moral, o refinado e o rudimentar, respectivamente.

Contudo, como ressalta Paulo César de Souza, na nota 97, ao capítulo Contribuição à história natural da moral, de Para além de bem e mal, § 186, o termo moral, 
[...] no texto de Nietzsche, não se limita à ética e aos bons costumes, mas abrange todas as coisas humanas - sentimentos, pensamentos, atos -, em oposição ao puramente físico, extra-humano, no mesmo sentido falava-se, há não muito tempo, de 'ciências morais' (NIETZSCHE, 2005, p. 214-215, grifo do autor, nota do tradutor).

A sensibilidade moral não se reduz à ética e aos bons costumes, ou a uma ciência da moral, mas abrange os impulsos e afetos humanos. Por outro lado, a ciência da moral é esta vontade de fundamentar a moral sem problematizá-la. Na perspectiva nietzscheana, pelo fato de a moral abarcar os impulsos e os afetos humanos, a sensibilidade moral moderna é tardia, múltipla, excitável e refinada, enquanto a pretensa ciência da moral que lhe corresponde é "ainda jovem, incipiente, tosca e rudimentar", pois ao tentar fundamentar a moral, não contempla a multiplicidade e as problemáticas da própria moral (NIETZSCHE, 2005, p. 74$75)$.

E mais, esse contraste é visível e toma "corpo na pessoa mesma de um moralista" (NIETZSCHE, 2005, p. 74), tendo em vista que é a figura do moralista que representa essa pretensão por fundamentar a moral, sem levar em consideração as configurações e multiplicidades da moral. Nesse sentido, o moralista é uma analogia de todos os filósofos que se fixaram exclusivamente na tarefa de fundamentação da moral. Na concepção de Nietzsche, Schopenhauer foi um dos filósofos que representou esse contraste.

\section{A ciência moral, a tipologia da moral e o problema da própria moral}

Considerando detidamente o que designa a expressão 'ciência da moral', Nietzsche declara que "a expressão 'ciência da moral' resulta demasiado arrogante e contrária ao bom gosto" (NIETZSCHE, 2005, p. 74, grifo do autor), sendo que o bom gosto é sempre antecipado pela modéstia. Destarte, a ciência da moral é arrogante e contrária ao bom gosto devido a sua pretensão de fundamentar racionalmente a moral, desconsiderando a multiplicidade de morais que são expressões simbólicas dos impulsos e dos afetos humanos. A pretensão da ciência da moral não é somente arrogante; ela também é ambiciosa e complexa.

Nietzsche propõe, por outro lado, uma tarefa modesta ante a ambiciosa pretensão de fundamentação da moral, e é nesta modéstia que consiste o bom gosto. Todavia, no que consiste essa tarefa modesta? Ora, consiste na preocupação em estabelecer um procedimento histórico, visando à descrição da multiplicidade de morais, que implica na preparação de uma tipologia da moral. Como o próprio Nietzsche (2005, p. 74, grifo do autor) salienta, 


\section{Alêsing bra'}

IN' 2596-2671

Revista AlembrA - RA Confresa-MT

Volume 3. Número 6. Janeiro a junho 2021

[...] deveríamos, com todo o rigor, admitir o que se faz necessário por muito tempo, o que unicamente se justifica por enquanto: reunião de material, formulação e ordenamento conceitual de um imenso domínio de delicadas diferenças e sentimentos de valor que vivem, crescem, procriam e morrem e talvez tentativas de tornar evidentes as configurações mais assíduas e sempre recorrentes dessa cristalização viva - como preparação para uma tipologia da moral.

Ante a impossibilidade de engendrar uma ciência da moral, Nietzsche entende que para alcançar uma tipologia da moral é necessário o estabelecimento de uma via preparativa, a saber: "o que unicamente se justifica por enquanto" (NIETZSCHE, 2005, p. 74) - um procedimento histórico. Nietzsche ressalta que tal procedimento deve descrever as várias configurações de moral até então existentes, levando em consideração o conhecimento da imensidão de sentimentos e diferenças de valores que perpassam a história - o conhecimento a respeito de povos, tempos e eras -, tentando tornar visível em tipos as configurações de moral mais frequentes e que mais se repetem dessa constelação de morais.

No entanto, segundo Nietzsche (2005, p. 74, grifo do autor), essa tipologia da moral não é implementada, pois

[...] tão logo se ocuparam da moral como ciência, os filósofos todos exigiram de si, com uma seriedade tesa, de fazer rir, algo muito mais elevado, mais pretensioso, mais solene: eles desejavam a fundamentação da moral - e cada filosofia acreditou até agora ter fundamentado a moral; a moral mesma, porém, era tida como 'dada'.

Ora, ao se ocuparem da moral como ciência, os filósofos pretendiam, equivocadamente, a fundamentação da moral. No processo de fundamentar a moral, a moral mesma era estabelecida como dada, não entendendo que não há a moral, mas as configurações de moral. Em vista disso, no princípio do $§ 186$, Nietzsche (2005) critica a noção de moral como "dada", "dogmática”, "imposta", "não natural”, ressaltando que a sensibilidade moral não se limita à ética e aos bons costumes, mas abarca os impulsos e afetos humanos. Com efeito, fica nítido que "a descrição comparativa das diversas morais não tem qualquer relação com a pretensão de fundamentação de uma única moral" (BRUSOTTI, 2016, p. 20, grifo do autor).

A teoria nietzscheana ressalta que as tarefas de descrição das várias configurações de moral e as consequentes tipologias da moral estavam longe da arrogante e complexa pretensão dos filósofos de fundamentar a moral,

[...] precisamente porque os filósofos da moral conheciam os fatos morais apenas grosseiramente, num excerto arbitrário ou compêndio fortuito, como moralidade do seu ambiente, de sua classe, de sua Igreja, do espírito de sua 


\section{Alêtinbora'}

IN' 2596-2671

Revista AlembrA - RA Confresa-MT

Volume 3. Número 6. Janeiro a junho 2021

época, de seu clima e seu lugar - precisamente porque eram mal informados e pouco curiosos a respeito de povos, tempos e eras, não chegavam a ter em vista os verdadeiros problemas da moral - os quais emergem somente na comparação de muitas morais (NIETZSCHE, 2005, p. 74-75, grifo do autor).

Em outras palavras, os filósofos da moral conheciam os fatos morais de um modo incoerente, desconectando-os do contexto cultural e espaço-temporal. Na perspectiva nietzscheana, a tipologia da moral é plausível se instituída na comparação das distintas morais, tendo em vista que é no exercício comparativo que emergem os verdadeiros problemas da moral e, por conseguinte, os vários tipos de configurações de moral existentes culturalmente. Não por acaso, Nietzsche aponta a impossibilidade de uma ciência moral, propondo em contrapartida uma tipologia da moral.

A ciência da moral, na pretensa tarefa de fundamentar a moral, não concebia os verdadeiros problemas da moralidade. De acordo com Nietzsche (1999, p. 319, grifo do autor):

[...] em toda 'ciência da moral', até agora, faltou, por estranho que isso possa soar, o próprio problema da moral: faltou a suspeita de que aqui há algo de problemático. O que os filósofos denominavam 'fundamentação da moral' e exigiam de si era, visto à luz correta, somente uma forma erudita da boa fé na moral dominante, um novo meio de sua expressão, portanto um estado de coisas no interior de uma determinada moralidade e até mesmo, no último fundamento, uma espécie de negação de que essa moral possa ser captada como problema.

A tarefa filosófica de fundamentação da moral era tão-somente uma forma erudita da ingênua fé na moral vigente, circunscrita a um contexto histórico, sendo, portanto, uma negação da moral como um problema cultural e espaço-temporal. Nesse sentido, a fundamentação da moral seria o oposto de um exame, decomposição, dúvida, vivissecção dessa mesma crença na moral como um problema. Não à toa, segundo Nietzsche (1999), Schopenhauer é um exemplum dessa forma erudita de fundamentar a moral.

\section{$4 O$ fundamento da moral em Arthur Schopenhauer}

Na obra Sobre o fundamento da moral, Schopenhauer apresenta uma análise filosófica sobre a questão da moral, ressaltando que o fundamento da moral é a compaixão. Preliminarmente, ele estabelece a distinção entre princípio e fundamento, ao propor que

[...] o princípio ou a proposição fundamental mais elevada de uma ética é a expressão mais concisa para o modo de agir que ela prescreve, ou, se ela não tiver uma forma imperativa, para o modo de agir ao qual ela propriamente reconhece valor moral. É, assim, o guia delas para a virtude em geral, expressa 
por uma proposição, portanto o 'hó, $\mathrm{t}$ ' [que] da virtude. O fundamento de uma ética é, (...) 'dióti' [porque] da virtude, razão (SCHOPENHAUER, 1995, p. 40 , grifo do autor).

Com efeito, a proposição fundamental ou o princípio estabelecido na opus schopenhaueriana e que, por conseguinte, será fundamentada é o seguinte: "neminem laede, imo omines, quantum potes, iuva!"6 (SCHOPENHAUER, 1995, p. 44). Na concepção de Schopenhauer, todos os éticos e seus respectivos princípios morais, levando em consideração as diversas maneiras com que o vistam, concordam com a expressão neminem laede, imo omines, quantum potes, iuva e se esforçam para fundamentá-la.

A proposição fundamental supracitada, segundo Schopenhauer, constitui os dois aspectos da compaixão, a saber: "ações de justiça espontânea e de caridade desinteressada" (SCHOPENHAUER, 1995, p. 122), ações que denotam sentido moral. Aliás, o próprio Schopenhauer (1995, p. 124) salienta que

[...] ações do tipo mencionado são as únicas a que se atribui propriamente valor moral. Como o que é próprio e característico delas vemos a exclusão daquela espécie de motivos, por meio dos quais, ao contrário, procedem todas as ações humanas, a saber, o interesse próprio, no sentido amplo da palavra. Por isso a descoberta de um motivo interessado, mesmo que fosse único, suprimiria totalmente o valor moral de uma ação, ou mesmo agindo de modo acessório, o diminuiria. A ausência de toda a motivação egoísta é, portanto, o critério de uma ação dotada de valor moral.

Analisemos detidamente a proposição fundamental. Observa-se que o princípio da moral, como exposto por Schopenhauer, é estabelecido em uma proposição molecular. Conforme Santos Júnior (2008, p. 92), “como uma proposição molecular é formada por duas proposições atômicas, cada uma destas se refere a uma das duas classes de ações compassivas". Com isso, a primeira proposição, "não faças mal a ninguém [...]", refere-se à justiça; significando que "o 'eu' se opõe a causar sofrimento ao 'outro', sem se preocupar com as vantagens para si da afirmação de sua vontade sobre outras" (SANTOS JÚNIOR, 2008, p. 92, grifo do autor). Já a segunda proposição, “[...] mas antes ajuda a todos que puderes! [...]”, referese à caridade, significando que “o 'eu' age convocado por uma vontade distinta da sua, isto é, encontra-se clamado para agir para livrar outros seres do sofrimento" (SANTOS JÚNIOR, 2008, p. 92, grifo do autor). Desse modo, o sentido das ações centradas na proposição

\footnotetext{
6 “Não faças mal a ninguém, mas antes ajuda a todos que puderes!”.
} 
fundamental são a justiça e a caridade, as duas virtudes morais, o que assinala a compaixão como o cerne das ações morais no pensamento schopenhaueriano.

\section{Schopenhauer e a exaltação filosófica da moral cristã na perspectiva de Nietzsche}

Conforme Nietzsche, Schopenhauer apresenta sua tarefa de fundamentar a moral com uma inocência quase venerável (NIETZSCHE, 2005). Assim expressa Schopenhauer (1995, p. 44, grifo do autor):

[...] o princípio, a proposição fundamental sobre cujo conteúdo todos os éticos estão de acordo, por mais diversas maneiras com que o vistam - à expressão que tomo pela mais fácil e mais pura de todas: neminem laede, imo omines, quantum potes, iuva! [não faças mal a ninguém, mas antes ajuda a todos que puderes!]. Esta é propriamente a frase que todos os doutrinadores de moral esforçam por fundamentar [...] o próprio fundamento da ética que se procura há séculos, tal como a pedra filosofal.

Para Nietzsche (2005, p. 75), Schopenhauer é "um pessimista, um negador de Deus e do mundo, que se detém diante da moral", que reivindica a tarefa de fundamentar a moral, equacionando o problema da tese fundamental em torno do qual todos os éticos apresam a historicidade natural dos impulsos e afetos humanos, estabelecendo assim o único e mais puro fundamento da moral, cujo cerne estaria implícito na seguinte proposição: "neminem laede, imo omines, quantum potes, iuva! - não faças mal a ninguém, mas antes ajuda a todos que puderes!" (SCHOPENHAUER, 1995, p. 44).

Todavia, ao estabelecer a compaixão como o fundamento da moral, Schopenhauer não percebeu que a sua tarefa de fundamentação da moral resultou na exaltação filosófica de um determinado tipo de moral: a moral cristã. Assim, a figura de Schopenhauer representa o contraste entre a refinada sensibilidade moral moderna e a grotesca cegueira da ciência moral ante o problema da própria moral.

\section{Considerações Finais}

Percebe-se que no $\S 186$, de Para além de bem e mal, Nietzsche critica a pretensão clássica dos filósofos de fundamentar a moral, que engendraram uma ciência da moral, sem, contudo, levar em consideração a problemática da própria moral. Ao contrário, Nietzsche propõe uma tipologia da moral, um procedimento histórico, apontando para a necessidade de descrever e comparar as várias configurações de moral até então culturalmente existentes. Desse modo, ao formular esta crítica, Nietzsche atinge Arthur Schopenhauer, cuja 


\section{Alemishbra:}

IN' 2596-2671

Revista AlembrA - RA Confresa-MT

Volume 3. Número 6. Janeiro a junho 2021

fundamentação da moral estaria implícita na sentença: "Neminen laede, imo omines, quantum potes, iuva! - não faças mal a ninguém, mas antes ajuda a todos que puderes!" (SCHOPENHAUER, 1995, p. 44).

Assim esclarecemos a tarefa e razões schopenhauerianas de fundamentação da moral, tal como Nietzsche a apresenta em Para além de bem e mal, § 186, do capítulo Contribuição à história natural da moral, destacando que, ao fundamentar a moral, Schopenhauer não se atentou para o fato de que a sua tarefa erudita resultou na exaltação filosófica de um tipo determinado de moral - a moral cristã.

\section{Referências}

BRUSOTTI, Marco. Descrição comparativa versus fundamentação: o quinto capítulo de Para Além de Bem e Mal: "Contribuição à história natural da moral". Cadernos Nietzsche, Guarulhos/Porto Seguro, v. 37, n. 1, p. 17-43, jan./jun. 2016. Tradução de William Mattioli; Revisão técnica de Rogério Lopes. Disponível em:

$<$ https://www.scielo.br/scielo.php?script=sci_arttext\&pid=S2316-

82422016000100017\&lng=en\&nrm=iso\&tlng=pt>. Acesso em: 14 fev. 2021.

GIACOIA JUNIOR, Oswaldo. Nietzsche \& Para além do bem e do mal. 2. ed. Rio de Janeiro: Jorge Zahar, 2005.

NIETZSCHE, Friedrich Wilhelm. Além do bem e do mal: prelúdio a uma filosofia do futuro. Tradução, notas e posfácio Paulo César de Souza. São Paulo: Companhia das Letras, 2005.

NIETZSCHE, Friedrich Wilhelm. Obras incompletas. Seleções de textos de Gérard Lebrun; tradução e notas de Rubens Rodrigues Torres Filho; posfácio de Antônio Cândido. São Paulo: Nova Cultural, 1999. (Os Pensadores).

SANTOS JUNIOR, Renato Nogueira dos. O fundamento da moral: Schopenhauer crítico de Kant. 2008. 152 f. Dissertação (Mestrado em Filosofia) - Universidade Federal de São Carlos, São Carlos, 2008.

SCHOPENHAUER, Arthur. Sobre o fundamento da moral. Tradução de Maria Lúcia Mello e Oliveira Cacciola. São Paulo: Martins Fontes, 1995. 